\title{
How Logical and Mathematical Games Treat Patients and Adults Suffering from Dementia
}

\author{
Vinothini Kasinathan ${ }^{1}$, Akansha Mandhana ${ }^{1}$, Aida Mustapha ${ }^{2}$, \\ Nur Sarah Adha Adam ${ }^{1}$
}

Sci. Journal Impact

Factor: 6.1 (2018)

ICV: 90.90 (2018)

cc) (i) (8)

Copyright@IJCRR

\author{
'School of Computing, Asia Pacific University of Technology and lnnovation, 57000 Kuala Lumpur, Malaysia; '²aculty of Computer Science \\ and Information System, Universiti Tun Hussein Onn Malaysia, 86400 Batu Pahat, Johor, Malaysia.
}

\section{ABSTRACT}

Research in recent years has proven the effectiveness of brain games for staving-off the onset of dementia as people we age. This is because games offer both social and mental stimulation especially old people with dementia. Games are good to exercise the brain and to slow down worsening cognitive capacity. Five types of games that are especially suitable for dementia lovers include card games, Bingo, visual games, word puzzles, and video games. To capitalize on this aspect, this paper reviews the potential of logical and mathematical games to induce mental health among the public in general, and old people as well patients of dementia in particular.

Key Words: Mathematical game, Dementia, Mental simulation

\section{INTRODUCTION}

According to the Merriam-Webster dictionary, the noun 'game' means an activity engaged in for diversion or amusement. In the existence of mankind, humans play certain games to lighten up their mood, have fun, or to distract themselves from other issues. In this era, however, games have become digitalized. It is a fact that every single person's normal life can include a normal or high rate of playing computer or video games even conventional non-digitalized games $^{1}$. Since the existence of phones, we have now come to a time when everyone has a mobile device, be it a laptop or a mobile phone. The mobile phones that we use are increased in quality every year as well as an increase in functionalities and features. It is because of this that the gaming industry has skyrocketed, especially with mobile phones now sometimes having better Graphics Processing Units (GPUs) than average laptops. Laptops, on the other hand, have become affordable items that can be deemed as necessities for our everyday lives.

Gaming addiction is also a prevalent issue at present times as many teens and children waste their time on games that do not increase their problem-solving skills and mental state. With gaming addiction, our youth has succumbed to it, with ongoing technological advancements making it easier for anybody with a tablet, mobile device, television, notebook computer or desktop to be able to play a game whenever boredom strikes ${ }^{2}$

Over $90 \%$ of children in the United States play video games, and quite a high amount of time is used playing them ${ }^{3}$. The problem is that with gaming addiction, the games that our youth sometimes play have no benefit to the brain or hardly give any increase in knowledge.

Aside from gaming addiction, it is also a known fact that social media can sometimes bring negative effects to its users, causing depression and other forms of negative emotions ${ }^{4}$. Both our youth, adults, and senior citizens can agree that not only does social media can spread positivity, but it can also spread negativity in the form of media, news, and posts that contain harsh, violent, and negative content that can disrupt moods and affect its readers. Public users must be educated with the types of games that can enhance critical thinking and problem-solving skills, not necessarily confined to educational materials for school children only.

As today's generation grows old in the future, the culture of playing video games has been long rooted in their behavioural routine. Health deterioration and complications will persist and we must prepare for technology or platform that could contribute to the mental health of senior people. To

\section{Corresponding Author:}

Vinothini Kasinathan, School of Computing, Asia Pacific University of Technology and Innovation, 57000 Kuala Lumpur, Malaysia; Email: vinothini@apu.edu.my

ISSN: $2231-2196$ (Print) ISSN: $0975-5241$ (Online)

Received: 12.06 .2020

Revised: 18.07 .2020

Accepted: 20.08 .2020

Published: 22.09 .2020 
capitalize on this aspect, this paper reviews the potential of logical and mathematical games to induce mental health among the public in general, and old people as well patients of dementia in particular.

The remaining of this paper proceeds as follows. Section 2 reviews in-depth two mental application games in the market. Section 3 discusses the findings and concludes the paper with some indication of future projects.

\section{REVIEW OF MENTAL GAMES}

This paper reviews in detail two highly popular mind games promoting problem-solving skills, which are Peak and Nonograms Katana. The main criterion of choosing the applications to review is based on the suitability of the concept to be adopted by different audience altogether, which is older people or patients with dementia. A study by O. Anderson ${ }^{5}$ reported the following key findings when researching attitudes and habits of adults age 50-plus in playing video games from a nationally representative sample of 2,964 adults ages 50-plus (gamers, $\mathrm{n}=1510$; non-gamers, $\mathrm{n}=1454$ ). The key findings are as follows:

- $\quad 38 \%$ of adults aged 50 -plus are gamers (every four in ten adults).

- $59 \%$ of the senior gamers use computers/laptops and $57 \%$ use the phone/other mobile devices.

- $59 \%$ of senior gamers say they play games online. $37 \%$ of $50-59$ year-olds play video games weekly but

- $43 \%$ of 60 -plus say they play every day.

- $22 \%$ of the senior gamers have made any video gamerelated purchases in the past 6 months.

- $77 \%$ bought for themselves, while $52 \%$ bought for others. Half of the online gamers report playing games online more today than they did five years ago.

Relative to this review, the top three favourite types of video games among the respondents are moreover, the main reason gamers say they are playing video games is to have fun $(26$ $\%$ say that's a very important factor and $52 \%$ say it's very important).

\section{RESULTS}

\section{Peak}

The peak is a mobile application developed by PeakLabs. It is a comprehensive collection of exercises designed to hone the player's memory, sharpen their problem-solving skills, and enhance their mental agility. Figure 1 shows the screenshot of Peak and the user profile in Peak. Peak has a sleek logo design, showing how tech-savvy the organization deems to be. Vibrant colours often attract consumers to download your application.

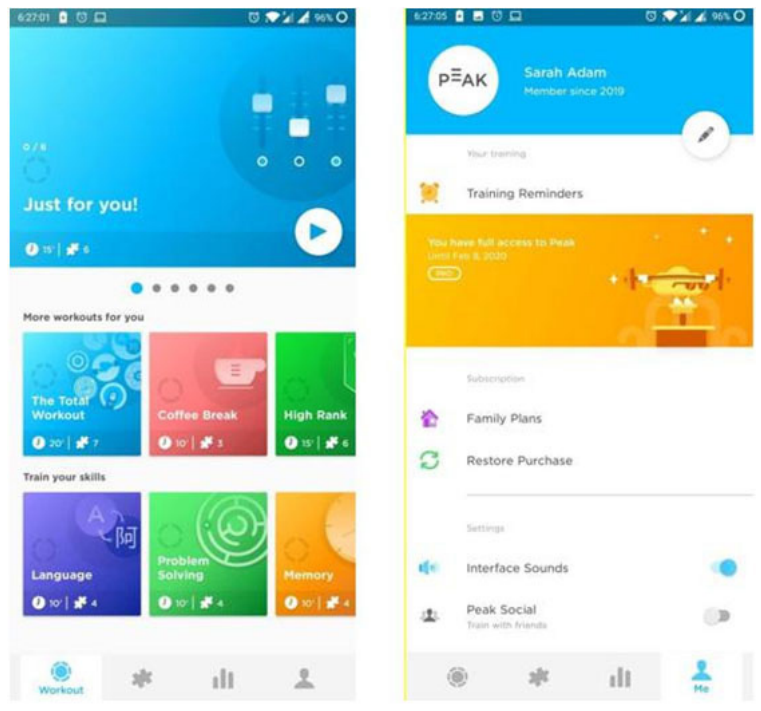

Figure 1: (a) Landing page of Peak (b) Personal profile in Peak.

In the profile page, the interface shows a user who bought a yearly subscription, during January 2019 and has full access to the application until the eighth of February, 2020. At the top half part, Peak curates a collection of games for users to play daily, and they change every single day. The amount of time that it would take for users to complete the curated playlist of games is stated there, as well as how many mental agility games are available in the said playlist. At the bottom half part, are games categorized with their purpose, which are The Total Workout, Coffee Break, High Rank, Language, Problem-Solving, and Memory? Figure 2 shows the problem-solving category and the summary of scores. Before the game begins, a summary of the player's score will be shown. The best rank, Legend is the highest rank available.

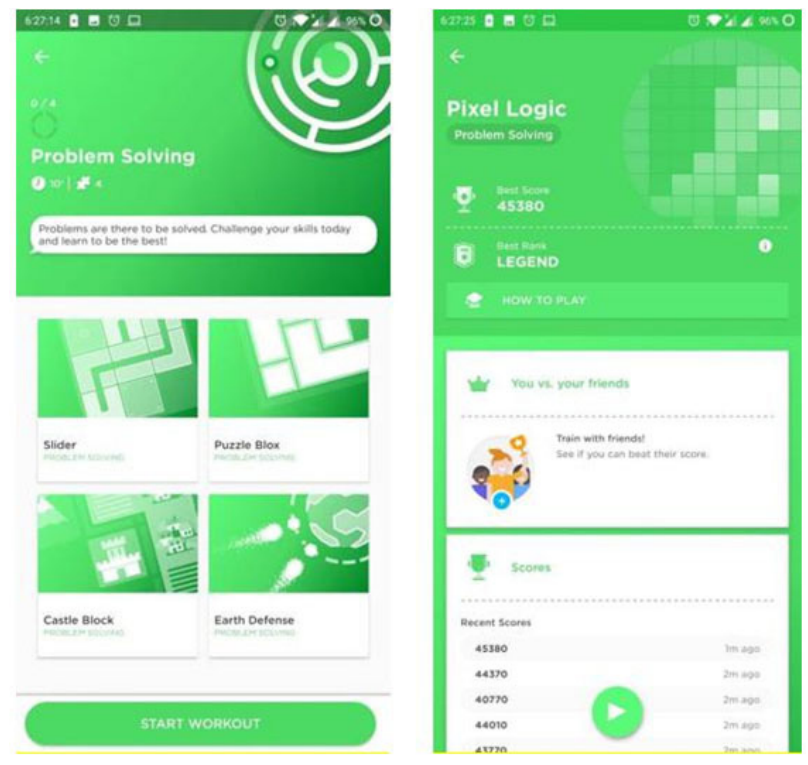

Figure 2: Interface for Problem-Solving Category and summary of scores. 
Figure 3 shows the gameplay. The game begins with a countdown timer on the top part of the game. At the bottom part of the game, there are tutorials which pop up now and then to remind users how to play. This game works in such a way that users have to fill boxes with black ink to confirm the placement of the answer. The horizontal and vertical sides have numbers to state how many boxes should be filled in. On the top right-hand corner of the game, is the score count. On the bottom left-hand corner of the game is the clue button, which will take away user's time should you choose to use it. The slash (/) symbol on the boxes is used when the user knows the box will never be filled in due to user calculations and logical assumptions.

Once the puzzle is done, it will show the shape that the developer has created; this time, it is in the shape of a heart, with the caption 'Love Message' as shown in Figure 3.
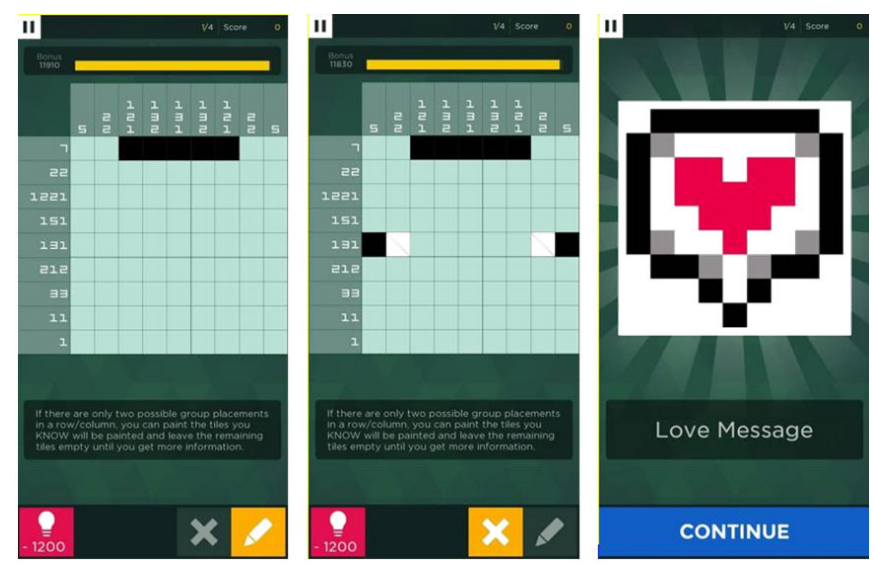

Figure 3: Gameplay with slash box-cancellers and completed nonograms.

\section{Nonograms Katana}

Nonograms Katana is developed by user 'devs'. The game has Japanese-like visuals, which makes it feel exclusive to the user. Figure 4 shows the landing page and the menu in Nonograms Katana. The options include Black-and-White Nonograms, Coloured Nonograms, Nonograms Sent by Users, and an option for My Nonograms, which are puzzles already completed by the user.

The mobile application, there are options to choose how big the player wants their Nonograms to be. Players generally choose the $10 \times 10$ option, while beginners can choose the $5 \times 5$. A tutorial is also provided by the application for users who do not know how to play. This is great for players who do not want to search online for the rules of the game.
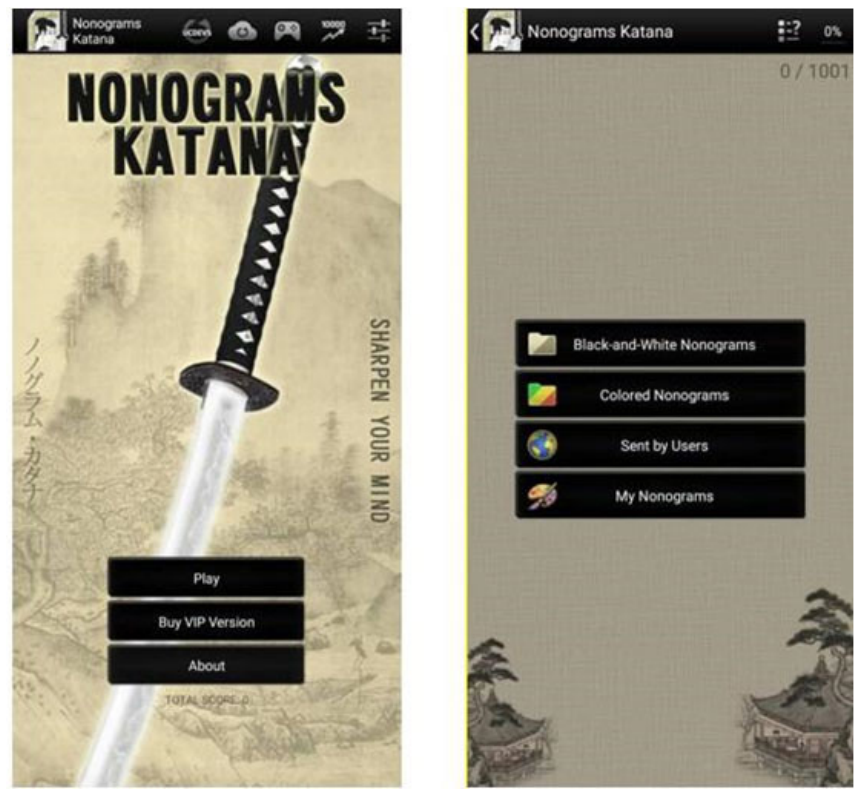

Figure 4: Landing page and application menu for Nonograms Katana.

Figure 5 shows the gameplay of Nonograms Katana. Puzzles are solved by using calculations and logical assumptions. On the top, left-hand corner of the game, a small, rough drawing of the 'picture' so far is shown, awaiting for the player's completion and accomplishment. Users can use the $\mathrm{X}$ tool to fill that in, in boxes that the developer confirms would not be filled. The developer continues the puzzle. When a grave mistake has been made, it will be highlighted in red to show the illogicality of it as shown in Figure 6 . The user will be encouraged to change their answer.
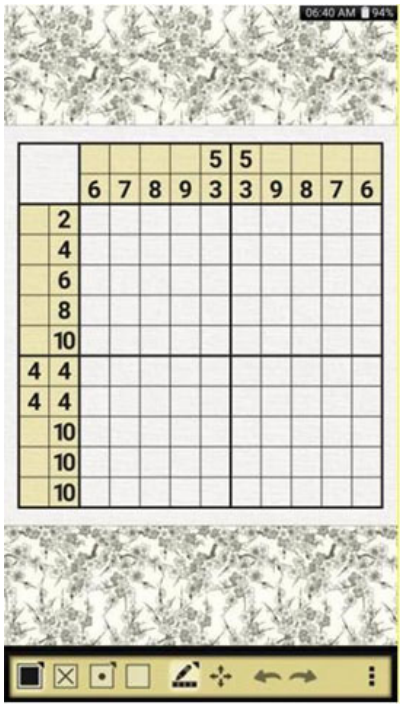
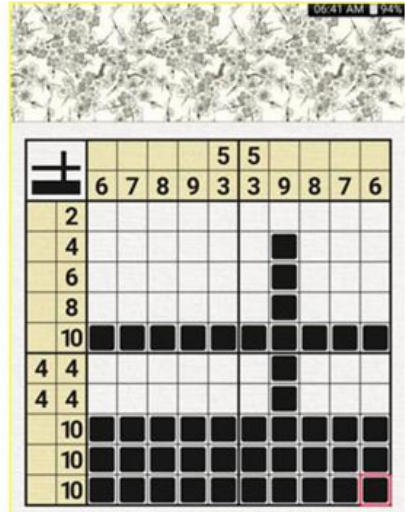

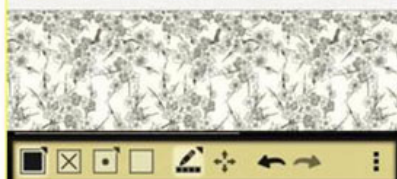

Figure 5: Gameplay for Nonograms Katana. 


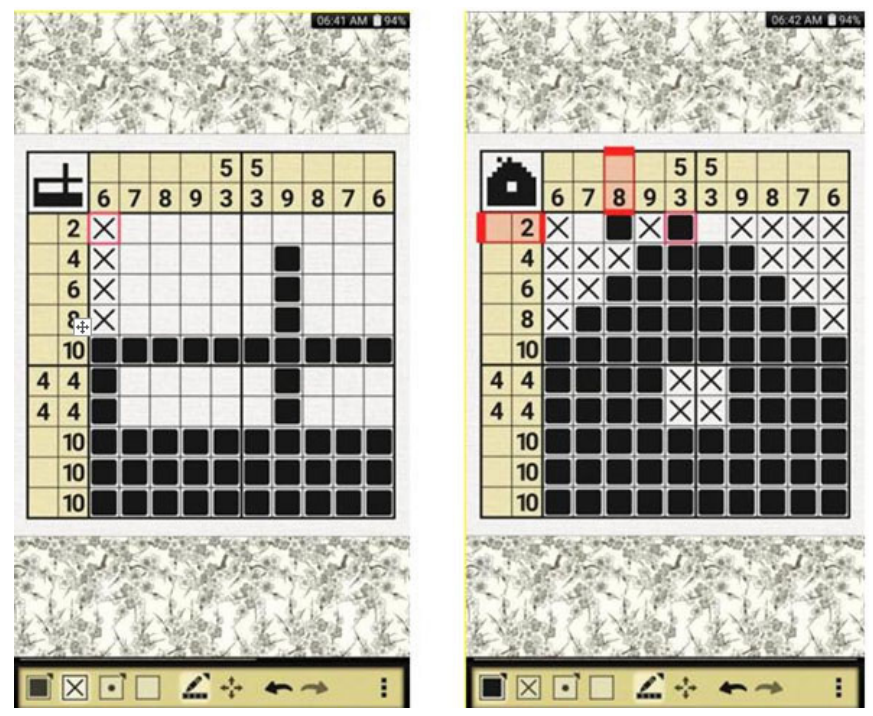

Figure 6: More gameplay for Nonograms Katana.

Finally, Figure 7 shows the completed nonogram. Note that a nonogram corresponds to a puzzle game with the objective is to an image on a grid by checking the certain cells. Those cells have to satisfy some rules associated with each row and column $^{6}$. In this figure, the $10 \times 10$ Nonogram is complete, its $\mathrm{X}$-filled boxes disappeared due to the completion of the puzzle. Here, a house is shown.
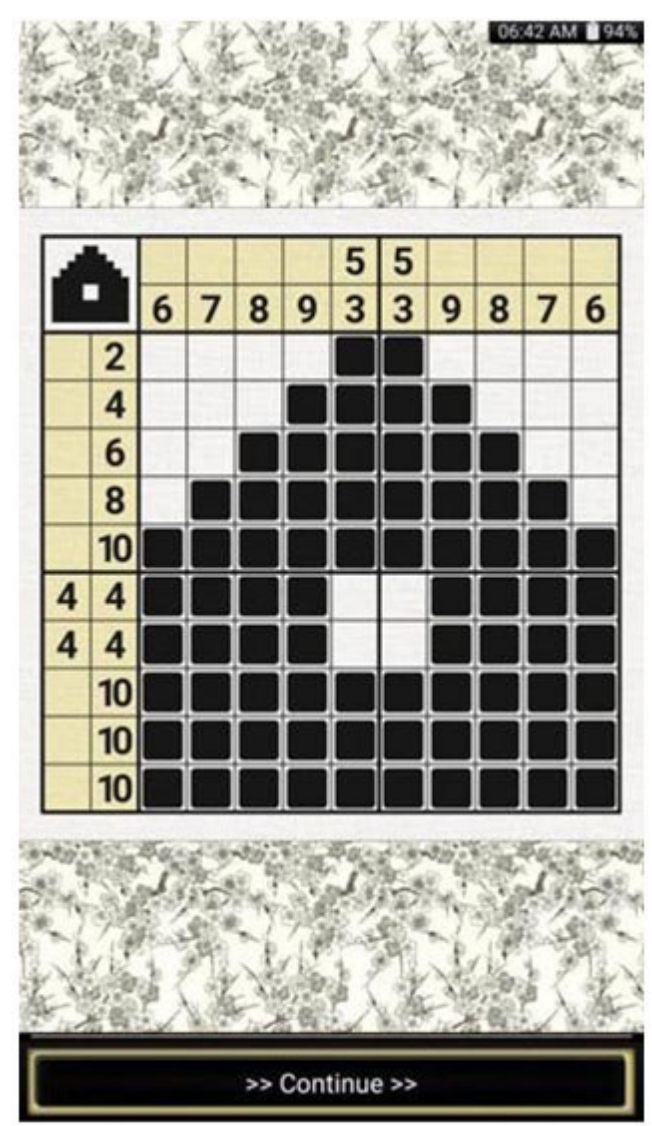

Figure 7: Completed nonogram in Nonograms Katana.

\section{CONCLUSIONS}

According to to ${ }^{7,8}$ maze and puzzle games train long term memory, spatial cognition, and analytical thinking. With this literature review as well as comparisons of similar gaming the application that exists in the market, many issues in regards to the prospectus, gaming application can be discovered and prepared for. By comparing similar systems, we can plan what kind of features most important or has not been offered in the market when preparing for a mental game application.

With this review, this project is set to embark on developing a problem solving and critical thinking games that are tailored for senior people target market, preferably within the age range of 60 to 70 years old. Such games are hoped to promote brain activities among the old people to safeguard them from having dementia. Dementia, although its not a fatal illness, is counted as a disability by the Equality Act 2010 and the UN Convention on the Rights of Persons with Disabilities (UNCRPD) as it causes long-term impairments of physical, mental, intellectual, as well as sensory ${ }^{9}$. It is imperative that our community is prepared with technology-based instruments for encouraging mental health in Malaysia.

\section{ACKNOWLEDGEMENTS}

The authors also wish to express gratitude to the management of Asia Pacific University of Technology \& Innovation (APU) for their support.

\section{Conflict of Interest}

The authors involved in the current study does not declare any competing conflict of interest.

\section{Funding and Sponsorship}

No fund or sponsorship in any form was obtained from any organization for carrying out this research work.

\section{REFERENCES}

1. M. H. Al-Bayed and S. S. A. Naser, "An intelligent tutoring system for health problems related to the addiction of video game playing," 2017.

2. C. Atkinson, G. Dileo, B. Erdik, J. Gleason, V. Hazzard, O. Hernandez, M. Laflamme, L. Romig, and H. Shafir, "Nokia has just updated the bud-get Nokia 3 to android 9.0 pie," https://www. addictions.com/video-games/Fig. 6: More gameplay for Nonograms Katana alarming-video-game-addiction-statistics/, 2018.

3. D. A. Gentile, K. Bailey, D. Bavelier, J. F. Brockmyer, H. Cash, S. M. Coyne, A. Doan, D. S. Grant, C. S. Green, M. Griffiths et al., "Internet gaming disorder in children and adolescents," Pediatrics, vol. 140, no. Supplement 2, pp. S81-S85, 2017.

4. M. Anderson, J. Jiang et al., "Teens, social media \& technology 2018," Pew Research Center, vol. 31, p. 2018, 2018. 
5. O. Anderson, "Video games: Attitudes and habits of adults age 50-plus," https://doi.org/10.26419/res.00125.001, 2016.

6. R. Soto, B. Crawford, C. Galleguillos, and E. Olgu'1n, "Solving nonogram using genetic algorithms," in 2016 11th Iberian Conference on Information Systems and Technologies (CISTI). IEEE, 2016, pp. 1-4.

7. P. M. Kato, "Video games in health care: Closing the Gap," Review of general psychology, vol. 14, no. 2, pp. 113-121, 2010.
8. I. Spence and J. Feng, "Video games and spatial cognition," Review of General Psychology, vol. 14, no. 2, pp. 92-104, 2010.

9. S. Fraser Butlin, "The UN Convention on the Rights of Persons with Disabilities: Does the Equality Act 2010 Measure up to UK International Commitments?" Industrial Law Journal, vol. 40, no. 4, pp. 428-438, 12, 2011. [Online]. Available: https://doi. org/10.1093/indlaw/dwr015 